\title{
Post Annealing Effects on Iron Oxide Nanoparticles Synthesized by Novel Hydrothermal Process
}

\author{
Ki-Chul Kim ${ }^{1}$ and Young-Sung Kim ${ }^{2 *}$ \\ ${ }^{1}$ Department of Material Design Engineering, Mokwon University, Daejeon 302-729, Korea \\ ${ }^{2}$ Graduate School of NID Fusion Technology, Seoul National University of Science and Technology, Seoul 139-743, Korea
}

(Received 1 October 2010, Received in final form 11 November 2010, Accepted 23 November 2010)

\begin{abstract}
We have investigated the effects of post annealing on iron oxide nanoparticles synthesized by the novel hydrothermal synthesis method with the $\mathrm{FeSO}_{4} \cdot 7 \mathrm{H}_{2} \mathrm{O}$. To investigate the post annealing effect, the as-synthesized iron oxide nanoparticles were annealed at different temperatures in a vacuum chamber. The morphological, structural and magnetic properties of the iron oxide nanoparticles were investigated with high resolution $\mathrm{X}$-ray powder diffraction (XRD), high resolution transmission electron microscopy (HRTEM), Mössbauer spectroscopy, and vibrating sample magnetometer analysis. According to the XRD and HRTEM analysis results, as-synthesized iron oxide nanoparticles were only magnetite $\left(\mathrm{Fe}_{3} \mathrm{O}_{4}\right)$ phase with face-centered cubic structure but post annealed iron oxide nanoparticles at $700^{\circ} \mathrm{C}$ were mainly magnetite phase with trivial maghemite $\left(\gamma-\mathrm{Fe}_{2} \mathrm{O}_{3}\right)$ phase which was induced in the post annealing treatment. The crystallinity of the iron oxide nanoparticles is enhanced by the post annealing treatment. The particle size of the as-synthesized iron oxide nanoparticles was about $5 \mathrm{~nm}$ and the particle shape was almost spherical. But the particle size of the post annealed iron oxide nanoparticles at $700^{\circ} \mathrm{C}$ was around $25 \mathrm{~nm}$ and the particle shape was spherical and irregular. The as-synthesized iron oxide nanoparticles showed superparamagnetic behavior, but post annealed iron oxide nanoparticles at $700{ }^{\circ} \mathrm{C}$ did not show superparamagnetic behavior due to the increase of particle size by post annealing treatment. The saturation of magnetization of the as-synthesized nanoparticles, post annealed nanoparticles at $500{ }^{\circ} \mathrm{C}$, and post annealed nanoparticles at $700{ }^{\circ} \mathrm{C}$ was found to be $3.7 \mathrm{emu} / \mathrm{g}, 6.1 \mathrm{emu} / \mathrm{g}$, and $7.5 \mathrm{emu} / \mathrm{g}$, respectively. The much smaller saturation magnetization value than one of bulk magnetite can be attributed to spin disorder and/or spin canting, spin pinning at the nanoparticle surface.
\end{abstract}

Keywords : iron oxide nanoparticles, post annealing effect, hydrothermal process, Mössbauer spectra

\section{Introduction}

The magnetic nanoparticles are key materials for advancements in ferrofluids [1], biomedical applications such as medical diagnosis with contrast enhancement of magnetic resonance imaging (MRI) [2, 3], AC magnetic fieldassisted cancer theraphy [4], magnetic separation of bacteria [5], and isolation of genomic DNA and protein [6,7]. Many structural and magnetic studies have been published regarding ferrimagnetic magnetite or maghemite nanoparticles. It is important to establish the synthesis conditions to control the size and shape of the iron oxide nanoparticles to possibly tune their properties to a specific application. After the synthesis of the nanoparticles, thermal treatment provides a powerful method to optimize the

*Corresponding author: Tel: +82-2-970-6804

Fax: +82-2-970-6011, e-mail: youngsk@snut.ac.kr morphological and magnetic properties of the iron oxide nanoparticles [8].

The several techniques have been used for the synthesis of iron oxide nanoparticles, which including coprecipitation of ferrous $\left(\mathrm{Fe}^{2+}\right)$ and ferric $\left(\mathrm{Fe}^{3+}\right)$ ions by a base in an aqueous solution [9], thermal decomposition of iron pentacarbonyl $\left(\mathrm{Fe}(\mathrm{CO})_{5}\right)$ in the presence of oleic acid followed by oxidation [10], and organic solution-phase decomposition of the iron precursor at high temperature [11]. In this study, the iron oxide nanoparticles were synthesized by the novel hydrothermal process with the $\mathrm{FeSO}_{4} \cdot 7 \mathrm{H}_{2} \mathrm{O}$ using ultrasonic homogenizer followed basket milling. This process is economic, nontoxic, and environmental-friendly process suitable for mass production. The $\mathrm{FeSO}_{4} \cdot 7 \mathrm{H}_{2} \mathrm{O}$ is a low cost residuum of synthesis of $\mathrm{TiO}_{2}$. The low cost, mass production and environmental-friendly process are very important issues to practical applications. The morphological, structural and magnetic properties of 
the as-synthesized iron oxide nanoparticles and post annealed iron oxide nanoparticles from $400{ }^{\circ} \mathrm{C}$ to $700{ }^{\circ} \mathrm{C}$ were investigated with various analysis including high resolution X-ray powder diffraction (XRD), high resolution transmission electron microscopy (HRTEM), Mössbauer spectroscopy, and vibrating sample magnetometer analysis.

\section{Experimental Details}

To synthesize the iron oxide nanoparticles, $2.0 \mathrm{~g}$ of $\mathrm{FeSO}_{4} \cdot 7 \mathrm{H}_{2} \mathrm{O}$ was dissolved in $225 \mathrm{ml}$ deionized (DI) water, and $60 \mathrm{mg}$ of $\mathrm{KNO}_{3}$ and $0.56 \mathrm{~g}$ of $\mathrm{NaOH}$ were dissolved in $90 \mathrm{ml} \mathrm{DI}$ water. The two solutions were heated to 75 ${ }^{\circ} \mathrm{C}$ and mixed the two solutions while stirring which was used a stirring rod not a magnetic stirring bar. A green suspension was formed and rapidly turned black. The mixed solution was heated to $90{ }^{\circ} \mathrm{C}$ for 10 minutes while stirring with a stirring rod. The ultrasonication with Ultrasonic Homogenizer (Han Tech Co.) at frequency $28 \mathrm{kHz}$ $\pm 200 \mathrm{~Hz}$ was performed to prevent agglomeration which was induced from van der Waals force in the initial stage of nanoparticle formation. The black suspension was cooled to room temperature and added $\mathrm{H}_{2} \mathrm{O}_{2}$ for oxidation. The sodium hydroxide was added to the cooled solution to neutralize and rinsed with DI water. The suspension was dispersed with DI water and milled with the basket milling machine. Finally the suspension was rinsed with DI water and dried in a dehydrofreezing machine. To investigate the post annealing effect, as-synthesized iron oxide nanoparticles were annealed in the range of $400{ }^{\circ} \mathrm{C}$ to $700{ }^{\circ} \mathrm{C}$ in a vacuum chamber for 30 minutes. The base pressure of the vacuum chamber was under $3 \times 10^{-6}$ Torr which was achieved by turbomolecular pump.

The crystallographic structural properties of the iron oxide nanoparticles were characterized by high resolution X-ray powder diffraction (XRD, Bruker AXS: D8 Discover), high resolution transmission electron microscopy (HRTEM, JEOL: JEM-3011). The HRTEM images got with 500,000 magnifications to observe the individual nanoparticle. The selected area diffraction (SAD) patterns of the iron oxide nanoparticles got to analyze the crystalline phase. The camera length was $50 \mathrm{~cm}$ in the SAD analysis. The magnetic properties of the iron oxide nanoparticles are characterized with the Mössbauer spectroscopy and the vibrating sample magnetometer (VSM, Princeton Measurement: MicroMag 3900) analysis at room temperature.

\section{Results and Discussion}

The XRD patterns of the as-synthesized iron oxide nanoparticles and post annealed iron oxide nanoparticles



Fig. 1. XRD patterns of the (a) as-synthesized iron oxide nanoparticles and (b) post annealed iron oxide nanoparticles at $700{ }^{\circ} \mathrm{C}$. Inset is magnified XRD patterns to compare JCPDS reference patterns of the iron oxides (No. 19-0629: magnetite, No. 39-1346: maghemite).

at $700^{\circ} \mathrm{C}$ were shown in Fig. 1 . The XRD peaks of the assynthesized iron oxide nanoparticles are coincided with the JCPDS reference patterns of iron oxides (No. 19-0629: magnetite $\mathrm{Fe}_{3} \mathrm{O}_{4}$ ). The XRD peaks of the post annealed iron oxide nanoparticles at $700^{\circ} \mathrm{C}$ are larger and sharper than those of the as-synthesized iron oxide nanoparticles. It can be attributed to the increase of crystallinity of the iron oxide nanoparticles by post annealing treatment. Inset of Fig. 1 is magnified XRD patterns to compare JCPDS reference patterns of iron oxides (No. 19-0629: magnetite $\mathrm{Fe}_{3} \mathrm{O}_{4}$, No. 39-1346: maghemite $\left.\gamma-\mathrm{Fe}_{2} \mathrm{O}_{3}\right)$. There was a shoulder which represented mixture of the magnetite phase and maghemite phase. The XRD results indicated that assynthesized iron oxide nanoparticles were magnetite phase but post annealed iron oxide nanoparticles at $700{ }^{\circ} \mathrm{C}$ were mainly magnetite phase with trivial maghemite phase which was induced in the post annealing process. The particle size of the iron oxide nanoparticles was estimated from the full width at half maximum of XRD (311) peak and two theta of the (311) plane diffraction peak using Scherrer's formula [12]. The particle size of the as-synthesized iron oxide nanoparticles and post annealed iron oxide nanoparticles at $700^{\circ} \mathrm{C}$ was $5 \mathrm{~nm}$ and $25 \mathrm{~nm}$, respectively.

The HRTEM analysis carried out to investigate more detailed structural properties of the iron oxide nanoparticles. The HRTEM images and SAD patterns of the as-synthesized iron oxide nanoparticles and post annealed iron oxide nanoparticles at $500^{\circ} \mathrm{C}$ and $700^{\circ} \mathrm{C}$ were shown in Fig. 2. The particle size of the as-synthesized iron oxide nanoparticles was about $5 \mathrm{~nm}$ and the particle shape 


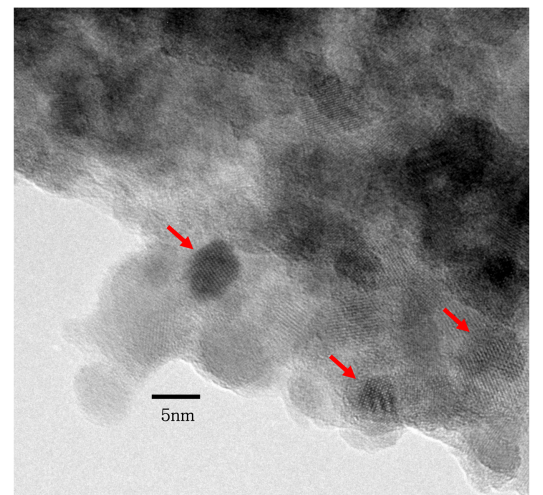

(a)

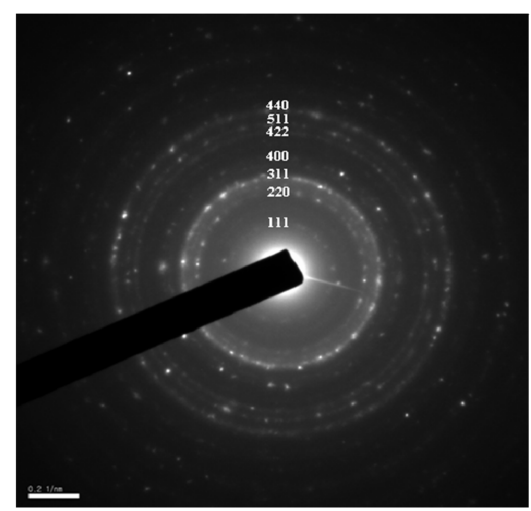

(d)

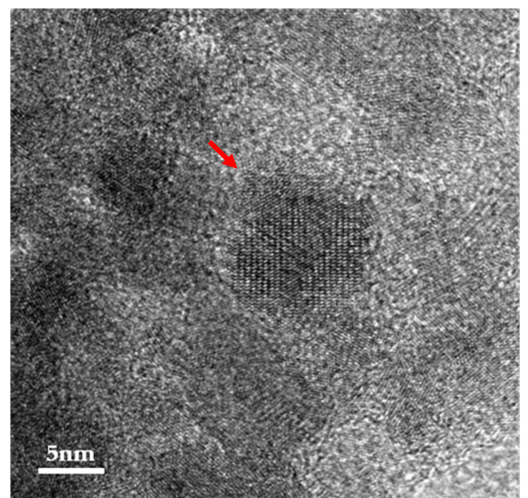

(b)



(e)

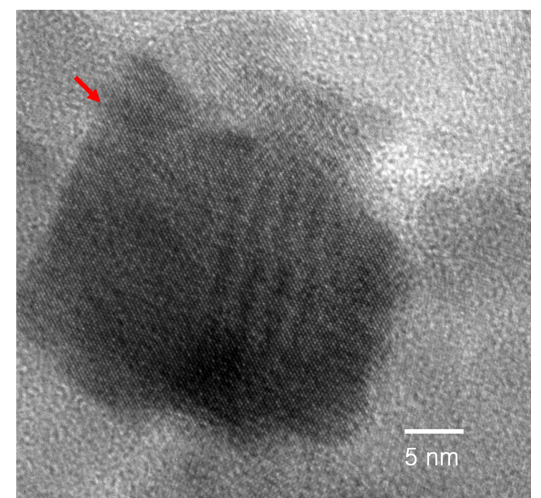

(c)

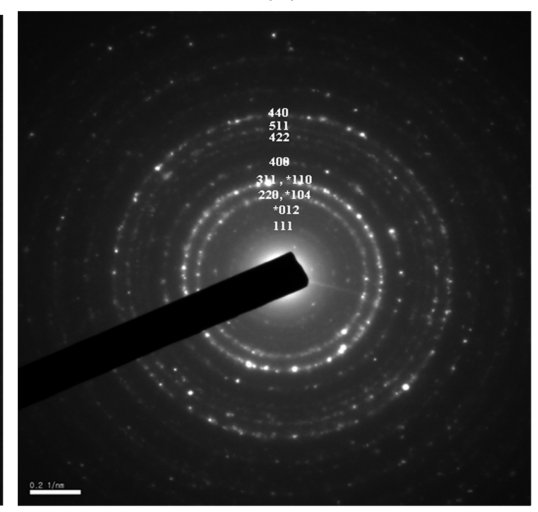

(f)

Fig. 2. HRTEM images of the (a) as-synthesized iron oxide nanoparticles, (b) post annealed iron oxide nanoparticles at $500{ }^{\circ} \mathrm{C}$, (c) post annealed iron oxide nanoparticles at $700^{\circ} \mathrm{C}$, and the SAD patterns of the (d) as-synthesized iron oxide nanoparticles, (e) post annealed iron oxide nanoparticles at $500^{\circ} \mathrm{C}$, (f) post annealed iron oxide nanoparticles at $700^{\circ} \mathrm{C}$. The asterion $(*)$ represents the maghemite phase.

was almost spherical. But the particle size of the post annealed iron oxide nanoparticles was gradually increased with increase of annealing temperature. The particle size of the post annealed iron oxide nanoparticles was around $10 \mathrm{~nm}, 15 \mathrm{~nm}, 20 \mathrm{~nm}, 25 \mathrm{~nm}$ at $400^{\circ} \mathrm{C}, 500{ }^{\circ} \mathrm{C}, 600^{\circ} \mathrm{C}$, and $700^{\circ} \mathrm{C}$, respectively. The particle shape of the post annealed iron oxide nanoparticles was almost spherical up to $600{ }^{\circ} \mathrm{C}$. But the particle shape of the post annealed iron oxide nanoparticles at $700^{\circ} \mathrm{C}$ was spherical and irregular (Fig. 2(c)). The increase of particle size and the change of particle shape are agreed with the previous report by J. M. Vargas et al. [13]. The structural properties of the iron oxide nanoparticles from HRTEM analysis agree with the XRD results. The SAD patterns of the post annealed iron oxide nanoparticles at $700^{\circ} \mathrm{C}$ are brighter and clearer than those of the as-synthesized iron oxide nanoparticles, which is due to the increase of crystallinity in the post annealing process. As shown in Fig. 2(f), the asterion(*) represents the maghemite phase which is induced in the post annealing process. It supports the XRD results.

The Mössbauer spectra of the as-synthesized iron oxide nanoparticles and post annealed iron oxide nanoparticles at $500{ }^{\circ} \mathrm{C}$ and $700^{\circ} \mathrm{C}$ were shown in Fig. 3. The spectra of the as-synthesized iron oxide nanoparticles are consisted with a central doublet which is corresponding to superparamagnetic state, and two Zeeman sextets. Mössbauer parameters are listed in Table 1. The cation distribution in magnetite $\left(\mathrm{Fe}_{3} \mathrm{O}_{4}\right)$ can be described by the formula $\mathrm{Fe}^{3+}\left[\mathrm{Fe}^{2+} \mathrm{Fe}^{3+}\right] \mathrm{O}_{4}$ with $\mathrm{Fe}$ cations without brackets on tetrahedral (A) sites and those in brackets on octahedral (B) sites of the cubic spinel lattice [14]. The Mössbauer spectrum of the as-synthesized iron oxide nanoparticles was fitted using the three magnetic components of hyperfine fields $H_{\text {hyp }, A}=486 \mathrm{kOe}$ corresponding to $\mathrm{Fe}^{3+}$ ions at tetrahedral sites $A$, and $H_{h y p, B}=452 \mathrm{kOe}, H_{h y p, B}=393 \mathrm{kOe}$ corresponding to $\left[\mathrm{Fe}^{2+} \mathrm{Fe}^{3+}\right]$ ions at octahedral site $B$ with the quadrupole splitting QS $=-0.013 \mathrm{~mm} / \mathrm{s},-0.005,0.047$ $\mathrm{mm} / \mathrm{s}$ and isomer shift IS $=0.205 \mathrm{~mm} / \mathrm{s}, 0.407 \mathrm{~mm} / \mathrm{s}$, and 0.238 , respectively. The Mössbauer spectra of the as-synthesized iron oxide nanoparticles indicate that as-synthesized iron oxide nanoparticles are magnetite phase. The as-synthesized iron oxide nanoparticles exhibit super- 


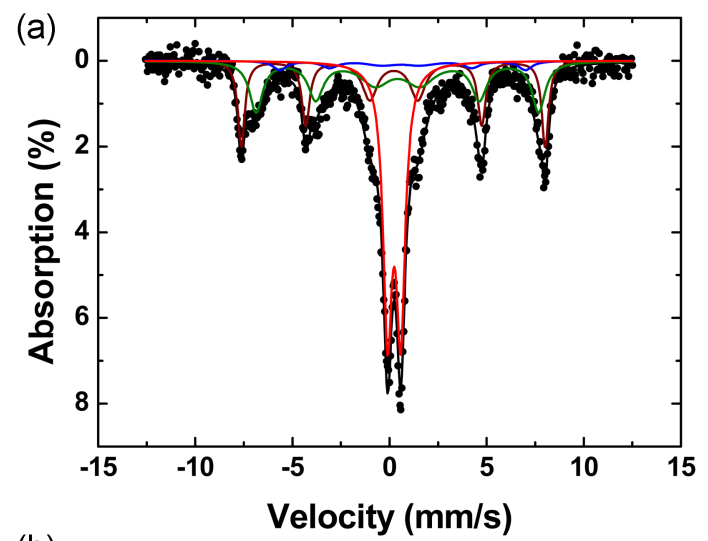

(b)


Fig. 3. The Mössbauer spectra of the (a) as-synthesized iron oxide nanoparticles, (b) post annealed iron oxide nanoparticles at $500{ }^{\circ} \mathrm{C}$, and (c) post annealed iron oxide nanoparticles at $700{ }^{\circ} \mathrm{C}$. The black solid lines are the best fits to experimental data (filled circles), and colored solid lines represent each component of the total fit.

paramagnetic phase with $37 \%$ spectral area. According to XRD and HRTEM analysis, the particle size of assynthesized nanoparticles is around $5 \mathrm{~nm}$ diameter, which exhibits superparamagnetic behavior. The rest portion of nonsuperparamagnetic state nanoparticles represents thermal relaxation effects with above $10 \mathrm{~nm}$ diameter [15]. If the as-synthesized iron oxide nanoparticles are monodispers- ed nanoparticles with $5 \mathrm{~nm}$ diameter, the spectra show only a central doublet [14]. The spectra of the post annealed iron oxide nanoparticles at $500{ }^{\circ} \mathrm{C}$ are consisted with the magnetite phase, maghemite phase, and superparamagnetic phase. The spectra of the post annealed iron oxide nanoparticles at $700{ }^{\circ} \mathrm{C}$ are consisted with the magnetite phase and maghemite phase. There was no superparamagnetic state due to the increase of the particle size. The particle size is an important parameter for superparamagnetic behavior. The magnetic nanoparticles with above $10 \mathrm{~nm}$ diameter have no superparamagnetic behavior [15]. According to the Mössbauer analysis, there was occurred partially phase change from magnetite to maghemite during the post annealing process at $500{ }^{\circ} \mathrm{C}$ and $700{ }^{\circ} \mathrm{C}$ with $7 \%$, $11 \%$ spectral area, respectively.

The hysteresis loops of the as-synthesized iron oxide nanoparticles and post annealed iron oxide nanoparticles at $500^{\circ} \mathrm{C}$ and $700^{\circ} \mathrm{C}$ were shown in Fig. 4. The saturation magnetization $\left(M_{s}\right)$ of the iron oxide nanoparticles was found to be $3.7 \mathrm{eum} / \mathrm{g} 6.1 \mathrm{emu} / \mathrm{g}$, and $7.5 \mathrm{emu} / \mathrm{g}$ for the as-synthesized, post annealed at $500{ }^{\circ} \mathrm{C}$, and $700^{\circ} \mathrm{C}$, respectively. The saturation magnetization value of the bulk magnetite is $85 \sim 95 \mathrm{emu} / \mathrm{g}$ [16]. The measured $M_{s}$ value of the iron oxide nanoparticles was much lower than the bulk magnetite. Extremely low values of $M_{s}$ have been measured in ferrimagnetic spinel particles with $\mathrm{d} \leq 15 \mathrm{~nm}$, attaining values as small as $\approx 0.06 M_{\mathrm{s}}^{\text {bulk, }}$, where $M_{\mathrm{s}}^{\text {bulk }}$ were the corresponding values of the bulk materials [17-19]. Spin canting has been proposed as the mechanism for the $M_{s}$ reduction in spinel nanoparticles [20]. The origin of the $M_{s}$ reduction can be attributed to the spin disorder at the nanoparticle surface and/or spin pinning and spin canting at the nanoparticle surface [21].

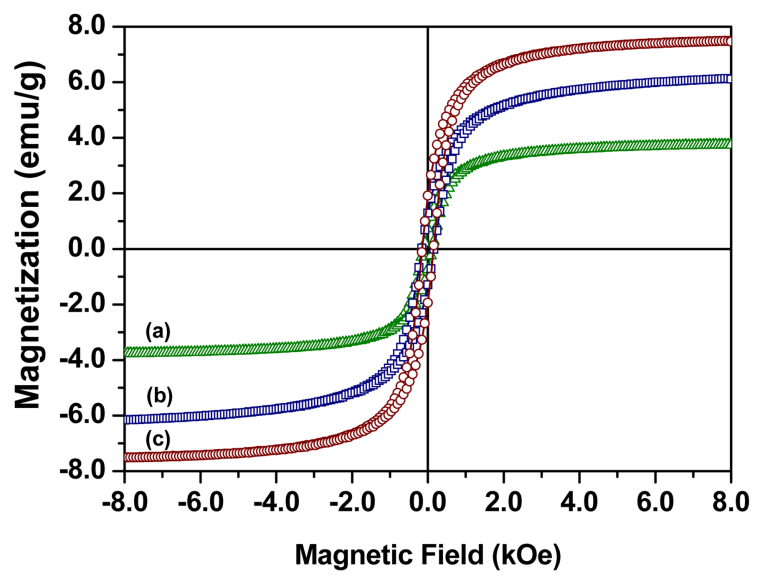

Fig. 4. Hysteresis curves of the iron oxide nanoparticles at room temperature: (a) as-synthesized iron oxide nanoparticles, (b) post annealed iron oxide nanoparticles at $500^{\circ} \mathrm{C}$, and (c) post annealed iron oxide nanoparticles at $700^{\circ} \mathrm{C}$. 
Table 1. Hyperfine parameters of iron oxide nanoparticles extracted from Mössbauer spectra at room temperature: magnetic hyperfine field $\left(\mathrm{H}_{f}\right)$, isomer shift (IS), quadrupole splitting (QS), and spectral area (Area).

\begin{tabular}{|c|c|c|c|c|c|c|c|}
\hline Sample & Phase & $\begin{array}{c}\mathrm{H}_{f} \\
(\mathrm{kOe})\end{array}$ & $\begin{array}{c}\text { Fe-ion } \\
\text { state }\end{array}$ & $\begin{array}{l}\text { Crystallne } \\
\text { Structure }\end{array}$ & $\begin{array}{c}\mathrm{IS} \\
(\mathrm{mm} / \mathrm{s})\end{array}$ & $\begin{array}{c}\mathrm{QS} \\
(\mathrm{mm} / \mathrm{s})\end{array}$ & $\begin{array}{c}\text { Area } \\
(\%)\end{array}$ \\
\hline \multirow{4}{*}{ As-Synthesized } & \multirow{3}{*}{$\mathrm{Fe}_{3} \mathrm{O}_{4}$} & $486(\mathrm{~A})$ & \multirow{2}{*}{+3} & Tetrahedral & 0.205 & -0.013 & 27.00 \\
\hline & & 452 (B) & & Octahedral & 0.407 & -0.005 & 30.20 \\
\hline & & 393 (B) & +2 & Octahedral & 0.628 & 0.047 & 5.62 \\
\hline & SPM & - & +3 & - & 0.238 & 0.680 & 37.18 \\
\hline \multirow{6}{*}{$\begin{array}{c}\text { Post- } \\
\text { Annealed } \\
\text { at } 500{ }^{\circ} \mathrm{C}\end{array}$} & \multirow{3}{*}{$\mathrm{Fe}_{3} \mathrm{O}_{4}$} & $486(\mathrm{~A})$ & \multirow{2}{*}{+3} & Tetrahedral & 0.181 & -0.019 & 29.61 \\
\hline & & 455 (B) & & Octahedral & 0.497 & -0.012 & 40.16 \\
\hline & & 410 (B) & +2 & Octahedral & 0.630 & 0.093 & 10.77 \\
\hline & & 478 & \multirow{2}{*}{+3} & Tetrahedral & 0.266 & -0.010 & 4.40 \\
\hline & $\gamma-\mathrm{Fe}_{2} \mathrm{O}_{3}$ & 438 & & Octahedral & 0.192 & 0.016 & 2.41 \\
\hline & SPM & - & +3 & - & 0.213 & 1.083 & 12.65 \\
\hline \multirow{5}{*}{$\begin{array}{c}\text { Post- } \\
\text { Annealed } \\
\text { at } 700{ }^{\circ} \mathrm{C}\end{array}$} & \multirow{3}{*}{$\mathrm{Fe}_{3} \mathrm{O}_{4}$} & 498 (A) & \multirow{2}{*}{+3} & Tetrahedral & 0.205 & 0.001 & 64.17 \\
\hline & & 481 (B) & & Octahedral & 0.178 & -0.019 & 18.15 \\
\hline & & 403 (B) & +2 & Octahedral & 0.700 & -0.056 & 6.79 \\
\hline & \multirow[b]{2}{*}{$\gamma-\mathrm{Fe}_{2} \mathrm{O}_{3}$} & 478 & \multirow[b]{2}{*}{+3} & Tetrahedral & 0.266 & -0.011 & 7.03 \\
\hline & & 438 & & Octahedral & 0.192 & 0.016 & 3.86 \\
\hline
\end{tabular}

Smaller nanoparticles have more disordered spins or spin pinning and spin canting than larger nanoparticles. The increase of the $M_{s}$ of the post annealed iron oxide nanoparticles can be attributed to the increase of the particle size and crystallinity by post annealing treatment. The increase of the coercive field of the post annealed iron oxide nanoparticles is due to the spin pinning at the irregular nanoparticle surface.

\section{Conclusions}

We have investigated the effect of post annealing on iron oxide nanoparticles synthesized by novel hydrothermal process. The crystallinity of the iron oxide nanoparticles is enhanced during the post annealing treatment in a vacuum chamber. The particle size of the post annealed iron oxide nanoparticles at $700^{\circ} \mathrm{C}$ is increased from $5 \mathrm{~nm}$ to $25 \mathrm{~nm}$. The particle shape of the post annealed iron oxide nanoparticles at $700^{\circ} \mathrm{C}$ is changed from spherical to spherical and irregular. According to the Mössbauer spectroscopy, as-synthesized iron oxide nanoparticles exhibit superparamagnetic behavior. As increase of the iron oxide particle size by post annealing treatment, superparamagnetic behavior is disappeared, and saturation magnetization of the iron oxide nanoparticles is increased slightly. The much smaller saturation magnetization value than one of bulk magnetite can be attributed to spin disorder and/or spin canting, spin pinning at the nanoparticle surface. According to the XRD, HRTEM, and Mössbauer spectroscopy analysis, there was occurred partially phase change from magnetite to maghemite during the post annealing process.

\section{References}

[1] Yu Lu, Yadong Yin, Brian T. Mayers, and Younan Xia, Nano Lett. 2, 183 (2002).

[2] D. K. Kim, Y. Zhang, J. Kehr, T. Klason, B. Bjelke, and M. Muhammed, J. Magn. Magn. Mater. 225, 256 (2001).

[3] Young-wook Jun, Yong-Min Huh, Jin-sil Choi, Jae-Hyun Lee, Ho-Tak Song, Sungjun Kim, Sarah Yoon, KyungSup Kim Jeon-Soo Shin, Jin-Suck Suh, and Jinwoo Cheon, J. Am. Chem. Soc. 127, 5732 (2005).

[4] A. Jordan, R. Scholz, P. Wust, H. Fahling, and R. Felix, J. Magn. Magn. Mater. 201, 413 (1999).

[5] J. Steingroewer, T. Bley, C. Bergemann, and E. Boschke, J. Magn. Magn. Mater. 311, 295 (2007).

[6] Z. M. Saiyed, C. Bochiwal, H. Gorasia, S. D. Telang, and C. N. Ramchand, Analytical Biochemistry 356, 306 (2006).

[7] Se Chan Kang, Yong Jun Jo, Jong Phil Bak, Ki-Chul Kim, and Young-Sung Kim, J. Nanosci. Nanotechnol. 7, 3706 (2007).

[8] Y. Chu, J. Hu, W. Yang, C. Wang, and Jin Z. Zhang, J. Phys. Chem. B 110, 3135 (2006).

[9] Fong-Yu Cheng, Chia-Hao Su, Yu-Sheng Yang, ChenSheng Yeh, Chiau-Yuang Tsai, Chao-Kiang Wu, MingTing $\mathrm{Wu}$, and Dar-Bin Shieh, Biomaterials 26, 729 (2005).

[10] Taeghwan Hyeon, Su Seong Lee, Jongnam Park, Yunhee Chung, and Hyon Bin Na, J. Am. Chem. Soc. 123, 12798 (2001). 
[11] Shouheng Sun and Hao Zeng, J. Am. Chem. Soc. 124, 8204 (2002).

[12] G. Sanon, R. Rup, and A. Mansingh, Thin Solid Films 190, 287 (1990).

[13] J. M. Vargas, E. Lima, Jr., L. M. Socolovsky, M. Knobel, D. Zanchet, and R. D. Zysler, J. Nanosci. Nanotechnol. 7, 3313 (2007).

[14] Gerado F. Goya, Solid State Commun. 130, 783 (2004).

[15] G. F. Goya, T. S. Berquo, F. C. Fonseca, and M. P. Morales, J. Appl. Phys. 94, 3520 (2003).

[16] S. Chikazumi, Physics of Magnetism, Wiley, New York
(1964) p. 100.

[17] R. H. Kodama, A. E. Berkowitz, E. J. McNiff, and S. Foner, Phys. Rev. Lett. 77, 394 (1996).

[18] B. Martinez, X. Obradors, L. Balcells, A. Rouanet, and C. Monty, Phys. Rev. Lett. 80, 181 (1998).

[19] T. Lutz, C. Estouvnes, and J. L. Guille, J. Sol-Gel Sci. Technol. 13, 929 (1998).

[20] H. Kachkachi and M. Dimian, Phys. Rev. B 66, 174419 (2002).

[21] E. Lima, Jr., A. L. Brandl, A. D. Arelaro, and G. F. Goya, J. Appl. Phys. 99, 083908 (2006). 